\title{
Construction of SOA Based VR Technology in Animation Teaching
}

\author{
https://doi.org/10.3991/ijet.v13i05.8435 \\ Zhenyan Qin( $\left.{ }^{\square}\right)$ and Zonghua Tao \\ Anhui Jianzhu University, Hefei, China \\ zhenyanqin66@yeah. net
}

\begin{abstract}
D animation production is an animation course widely set up in colleges currently aiming at cultivating $3 \mathrm{D}$ animation production talents. But in actual teaching, there exist problems of teaching practice not prominent, teaching not intuitive, and students' learning interest not strong. Based on this condition, this paper plans to use SOA design and VR technology in teaching system design with the help of good information integration, service integration function of SOA design and advantages of VR technology of directly and dynamically reflecting object forms so as to improve teaching interesting-ness and intuition, help students to increase knowledge and improve teaching quality in relaxed atmosphere. Finally, this paper presents teaching effect comparison experiments which show that the virtual teaching system designed and developed in this paper can improve students' learning activity, teacher-student communication and obtain better teaching effect.
\end{abstract}

Keywords-SOA, VR technology, 3D animation production, teaching

\section{$1 \quad$ Introduction}

In recent years, with the continuous innovation of science and technology, animation industry is faced with technological reforms. Especially with the emerging of 3D animation technology, its simulated reality, dynamic and aesthetic animation images have greatly improved animation appreciation and brought chances for high-speed development of animation industry [1]. In front of increasingly huge market demand, colleges have additionally set up 3D animation production course to cultivate $3 \mathrm{D}$ animation production talents for animation enterprises and game companies. Meanwhile, under the influence of colorful 3D animation films, more and more students develop strong interest in 3D animation production course and choose this major as their future career direction [2]. Meanwhile, how to improve the teaching quality of this new course, cultivate qualified and excellent $3 \mathrm{D}$ animation production talents is an urgent problem. According to current research condition, the teaching quality off 3D animation production course is not satisfactory, graduates lack operational and practical ability, and talents capable of producing exquisite and excellent animation works are very scarce. Reason for this is traditional teaching methods are still used for $3 \mathrm{D}$ animation production course which is a discipline keeping pace with the times and 
having strong practical property. But using previous old teaching software has seriously restricted and prevented teaching quality improvement [3]. Detailed manifestations are: (1) Teaching method is still conservative. Teacher's instruction and students' listening mode is still used which is not good for highlighting students' subject position; (2) Teaching content is single which focuses on software teaching only or theoretical teaching only without unifying both so as not to cultivate excellent talents; 3. Class interaction is poor, and there is no communication between teachers and students. Lack of specific 3D animation production practice activity is not good for students' solidification and absorption of knowledge.

To improve teaching quality, it is necessary to change traditional teaching mode, apply new technology for auxiliary teaching, improve teacher-student interaction, and strengthen students' 3D animation production practice. Thus, this paper has chosen VR technology and popular SOA system design. VR technology as a technology using computer to simulate real environment can vividly display real people, objects, and provide vivid virtual scenes for students. It is good for software operation study, knowing animation figure and object characteristics, and improve students' activity. Meanwhile, using SOA system design can integrate school teaching resources, and integrate VR technology into teaching system. SOA based teaching system with good interaction and function of displaying virtual scenes, strengthening teacher-student communication, and adding virtual model can promote students' pre-class study and after-class practice, strengthen teacher-student communication. Combining both technologies can use their advantages to form a new teaching system suitable for 3D animation production course teaching demand so as to essentially change traditional teaching methods and teaching concepts for the purpose of cultivating 3D animation production talents.

\section{State of the art}

VR technology has been widely used in teaching very early. A lot of scholars and research institutions pay attention to researches in this area and gained some achievements. THU has established engineering mechanics virtual laboratory based on engineering experiment materials and applied VR technology to mechanics to simulate mechanics experiments and develop some auxiliary effect on control theory teaching and research [4]. Except for colleges, some companies have researched virtual teaching software development. Zhejiang Jinhuake Software Company has developed a set of virtual teaching software which is used for physics and chemical simulation, physics teaching, and playing physics realization process through animation, and knowing the phenomenon change in the whole process [5]. But the disadvantage is that it has not completely implemented 3D object modelling. Some experiments are in 3D images which have influenced the virtual effect. In foreign countries, Oxford has designed and developed a set of virtual chemical lab to vividly display each chemical phenomenon [6]. Clarkson University has developed basic circuit teaching system for circuit design and effect simulation to improve teaching practice. Oregon University has designed and developed virtual physics lab for simulating 
celestial body, mechanics, thermotic and other physics phenomenon to vividly display some invisible physical occurring principles and improve students' learning efficiency [7].

At present, SOA design has become the mainstream of future service structural design with huge potential and wide development. It is estimated that future teaching system will emphatically apply SOA design for improving teaching quality. However, there still exist some defects in China's SOA service virtual teaching technology. Firstly, animation teaching instruction is conducted by combing multimedia technology with 3D so as not to display some virtual scenes in actual class, which makes classroom lecturing boring, complicated and abstract; secondly, some virtual teaching technologies operate in complex manners so that some teachers in non-computer and information majors choose traditional multimedia teaching, which has hindered the promotion of virtual teaching technology and the development of information teaching technology [8]. Based on above defects, this research innovation proposes SOA virtual teaching system with teaching service as characteristics and apply Windows Embed Standard 7 system to input animation content into computer. It has convenient advantages of simple operation, low cost, no need of modification, usage after adjusting angles and directions.

\section{Theoretical construction}

\subsection{Dokeos and BigBlueButton}

SOA is mainly used in medical, telecommunication, finance, electricity and other industries in its application research and some achievements have been gained. In foreign countries, a lot of companies such as Geutsche Post, Credit Suisse use SOA design idea in system development so that systems are better than other design patterns in terms of practicability and construction cost. In domestic China, research and application in this area are not lagged behind. For example, Jiangshu Electric Power has applied SOA architectural pattern to integrate the information network in the whole province and achieved success. Through several years' development, more and more enterprises start applying SOA architectural pattern. According to investigation, half enterprises start using SOA. 13\% enterprises start development and design, 15\% enterprises have achieved information technology SOA design, $20 \%$ enterprises plan to use SOA design in the next one or two years, and plan to implement [9]. SOA as a component model can connect different function unit (called service) of application program through the well-defined interface and contract between these services. Interface defined by neutral way should be independent from hardware platform, operation system and programming language for service implementation so that services in various systems can be interactive in a unified and universal mode. The theoretical structure is shown on Fig 1.

It can be seen from Fig 1 that SOA system includes business services, enterprise services, application services, and infrastructure services [10]. Business services are abstract service defined as the core business operation executed in enterprise level. 


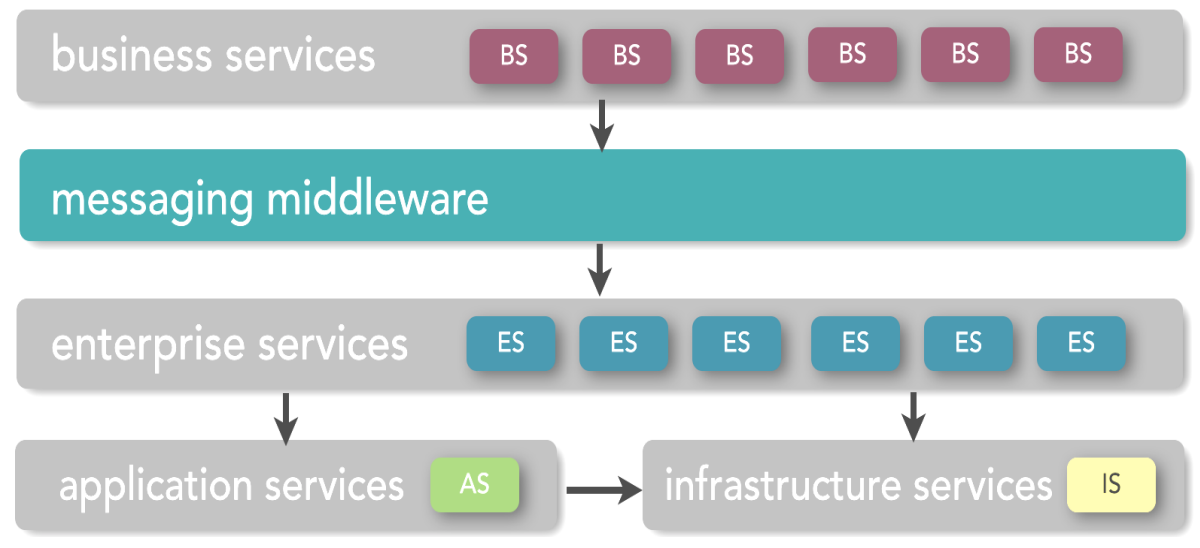

Fig. 1. Theoretical construction of SOA system

Enterprise service is a concrete service for achieving the functions defined by business services. Enterprise services have one-to-one or one-to-many congruent relationship with business services. Application services are specific to services of detailed application. Infrastructure services are similar with service-oriented architecture. These services are for achieving non-functionality task. In SOA, infrastructure service can be invocation of application services and enterprise services.

SOA design text can be implemented by Web services with advantages: Web services are widely used with mature technology, easy to use, low construction cost, and supportive for interoperability of solutions. Based on SOA design framework, by combining teaching system reality, this paper divides virtual teaching system into three-layer structure, i.e. service provision layer, service interface layer, and service use layer. Service provision layer function can set interface for various service so that users can choose different services. Service interface layer is the core layer of the whole system for blocking bottom system structure and providing service issuance and discovery functions. The service provision layer is mainly for service capsulation and new service interface reservation. Detailed structure is shown in Fig 2.

The service provision layer mainly contains two sub-modules: service capsulation module and message processing module. The service capsulation module is mainly to provide service interface. Their detailed works are as follows:

1. Capsulate the original traditional system in a service for the purpose of absorbing original information resource and unifying user interface.

2. Establish new service such as adding VR and 3D Max modeling function meanwhile reserve interface to prepare for adding new system in late stage.

Message processing module is for SOAP message processing between services. SOAP is a simple object access protocol. Its major work is as follows:

1. Receive and transmit SOAP messages

2. Master head processing of SOAP messages

3. Responsible for web service part 


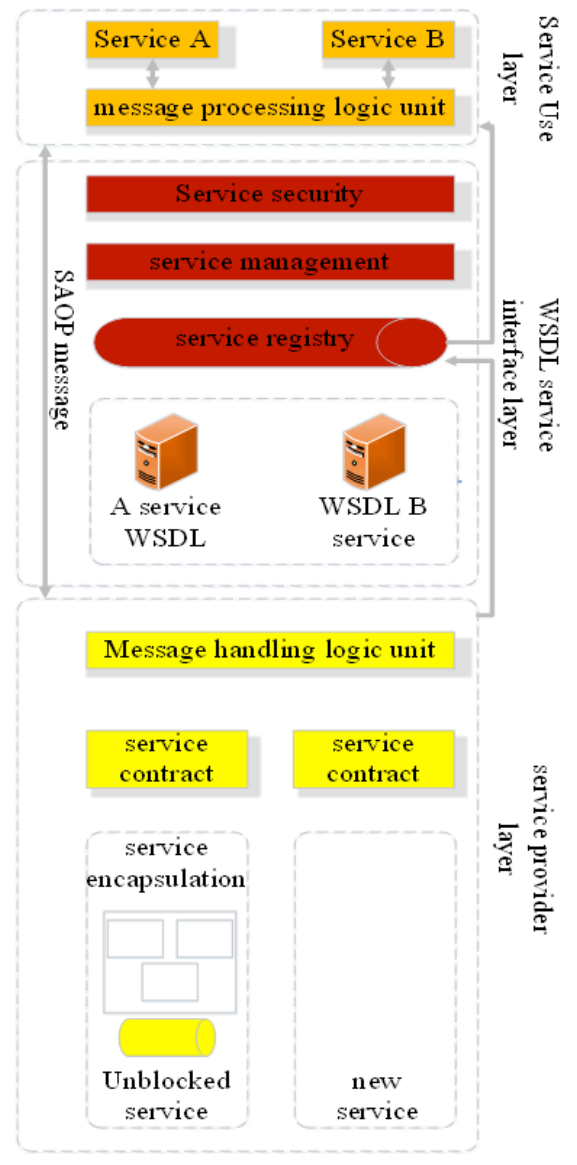

Fig. 2. System overall framework

Service interface layer is the core layer of framework. In a certain user service, service interface layer can inquire in service registration center and send service request to service provision layer to provide service. There are four component modules: service standard module, registration center module, management module and safety module.

Service use layer is the last layer of the whole system. Its specific work are as follows:

1. Provide unified abstract interface for users

2. As users do not know the position of service, specific architecture information, service layer uses blocking way to conceal this information.

3. Users can select different service types based on their demands.

After completing system framework design, teaching system design is completed after implementing different functions based on user demands. Teaching system hardware structure is shown in Fig 3. 


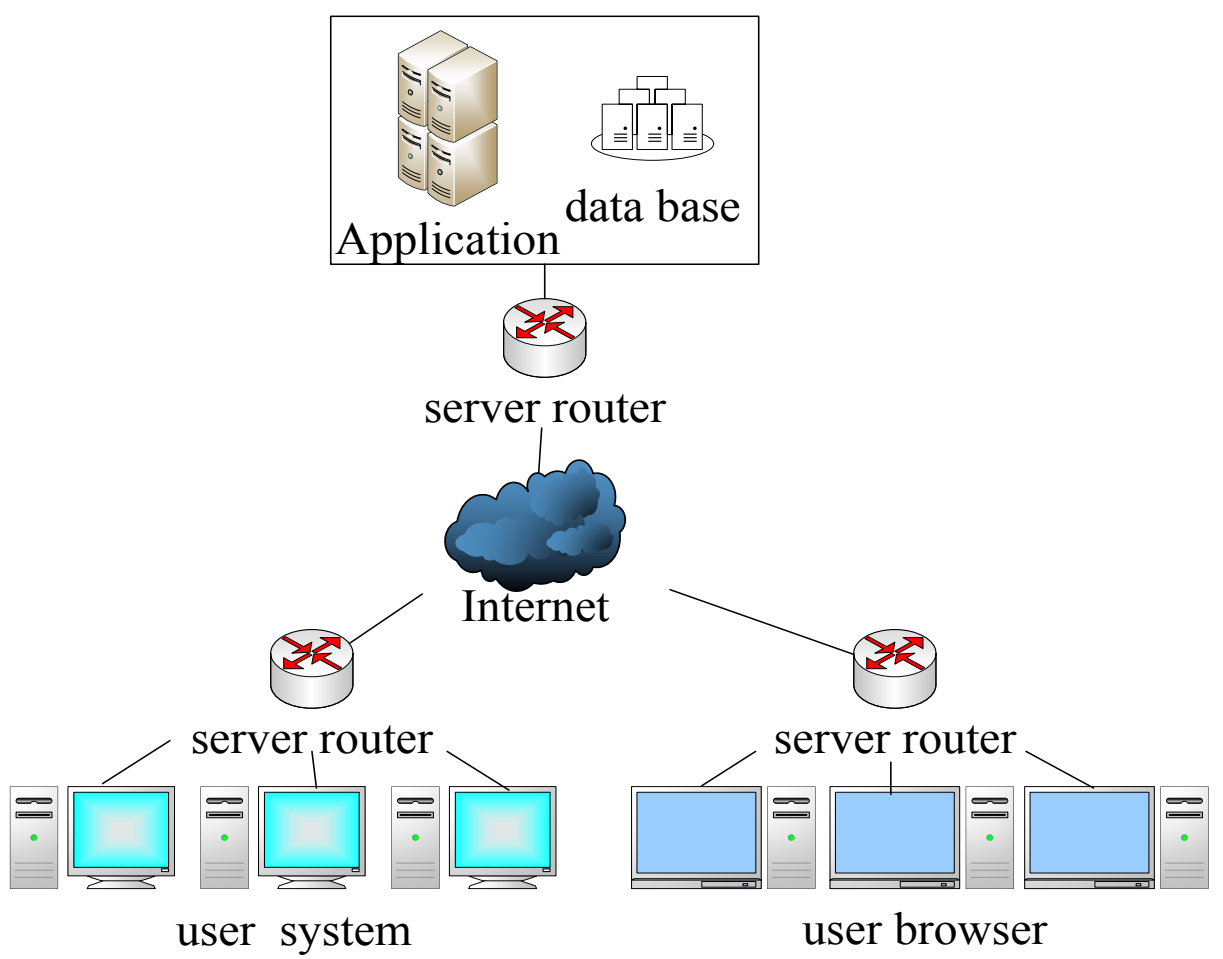

Fig. 3. System hardware structure

\section{SOA based virtual teaching system design}

SOA based virtual teaching system includes computer system, computer networks, and database. Computer system and network are designed with SOA but VR technology is used in database resources for lab, virtual lab devices, and other virtual scenes for subsequent virtual teaching. So, the technical implementation can be divided into two parts: a part is for SOA design and another part is for virtual modelling with VR technology.

\subsection{VR technology function design}

VR technologies used in this paper include AR technology and 3D technology. AR technology can map virtual world to the real work on screen and overlap virtual scenes and reality to achieve the interaction of both. 3D technology can turn planar images into $3 \mathrm{D}$ images through modelling. In terms of system function implementation, this paper mainly uses AR technology for object overlapping. 3D technology is used for object modelling to virtualize object real shape. VR function is made up by three parts including marker identification module, demonstrator rendering module and animation processing module. Specific structure is shown in Fig 4. 


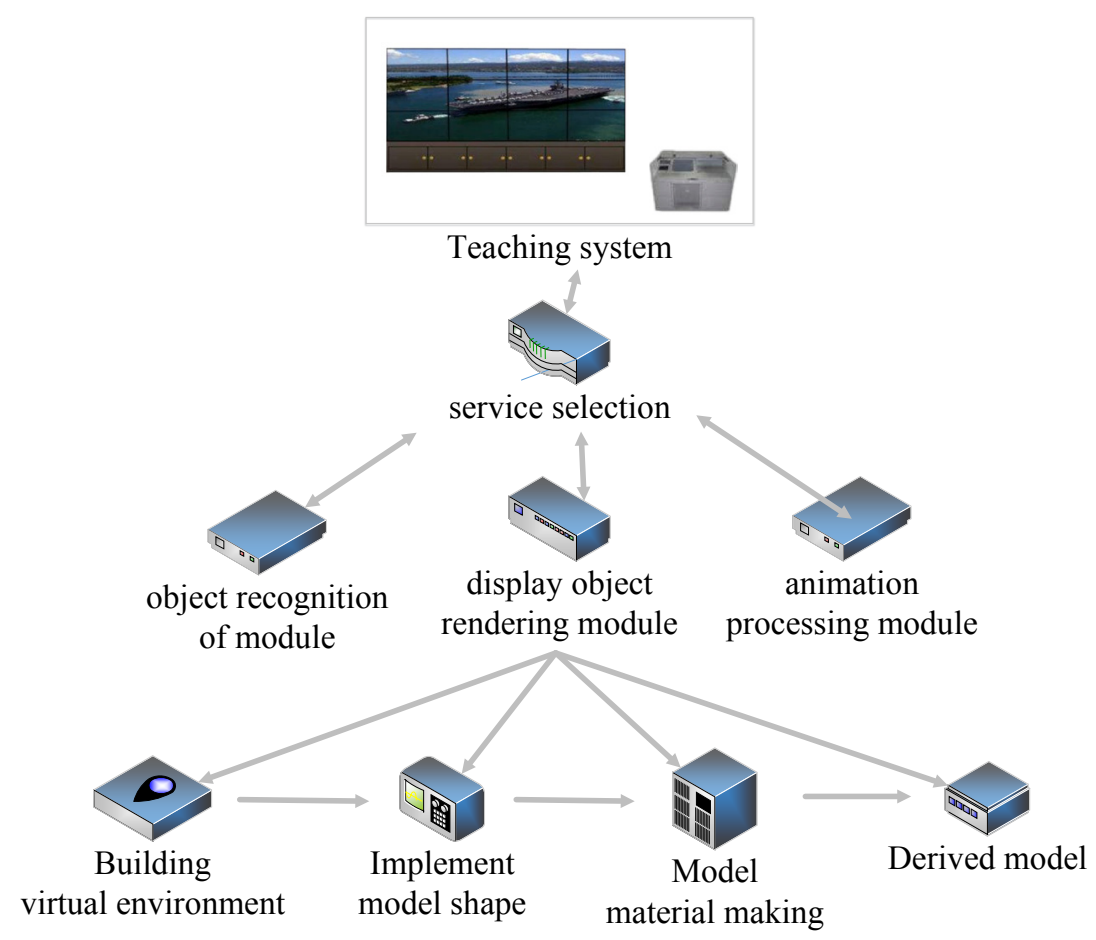

Fig. 4. VR function structure diagram

Object identification module is to recognize objects in video shooting images, differentiate different objects and map virtual objects to real environment with AR technology to achieve the interaction of both. For example, in 3D animation production course teaching, teachers can map animation figures or objects to real environment so that students can clearly observe object characteristics and input differentiate to animation images for students' better understanding and mastery.

Demonstrator rendering module is mainly for object post production processing with 3D technology so that I can accord with 3D scenes. 3D modelling is for the purpose of establishing a lifelike virtual scene so that students have a sense of substitution and stimulate their learning activity. The specific procedure of $3 \mathrm{D}$ modelling is shown in Fig 5.

In the beginning of modelling, establish a virtual environment firstly. Specifically, simulate the landform of the environment which is the basis of a virtual environment for carrying virtual figures and objects and highlighting object height. The next step is to implement model appearance. It is necessary to measure the rough outline ratio of complicated objects while modelling to build a model gradually and try to make it similar with its real look. Form simple objects with obvious geometric characteristics, template can be used for modelling so as to reduce workload. To make the virtualized model lifelike, it is necessary to make surface material except for similar appearance, i.e. the texture and color of model surface. There are two parts: early stage and post production. Light should be set up and material sphere should be created in the early 
stage; and then adjust model light and parameters in the late stage. After building model, the last step is to export the virtual model in the format of fbx. Before exporting, it is necessary to inspect the virtual model. Inspection contents include: whether the normal and model command is correct, how to modify problems, etc. After passing inspection, the final 3D model can be exported.

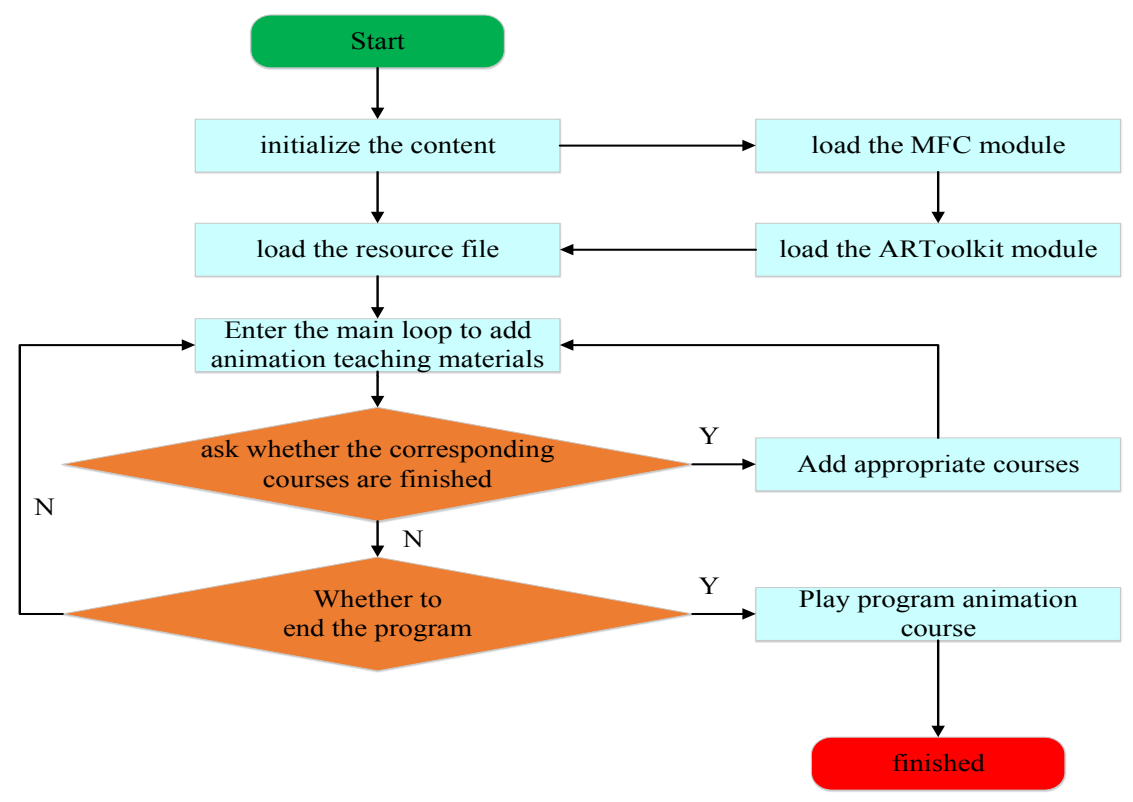

Fig. 5. 3D modelling procedure

Animation processing module is to directly display the 3D model through setting animation movements after adding animation effect. This module can make the virtualized model closer to real effect. For example, teacher can play a 3D dam model when instructing a dam structure. Students can watch dam translation, rotation and scaling through the system. After adding animation processing module, the dam current flowing scene can be demonstrated by playing the system. Teachers can instruct and explain through pausing and playing a certain movement.

\subsection{System implementation}

After completing system design, the next step is to implement system key technologies including XMLschema (XSD) definition, safety management, virtual reality service capsulation. Simple operation procedure is shown in Fig 5.

Fig 5 can show that, we define XSD as the message type transmitted while using service. Assume student number type as customerNum,String, passwords type as CustomerPassword,string, course name type as course,Stting.

Safety management is for protecting user information safety. Take online examination service safety strategy as the example, output message encryption is required. 
Assume user name as onlineexam, login passwords as onhneexam. VR service capsulation can add VR technology into system and implement VR teaching function. After completing VR service capsulation, this service can be used. System interface is shown in Fig 6. Fig 7 shows teaching procedure demonstration integrating VR technology and teaching.

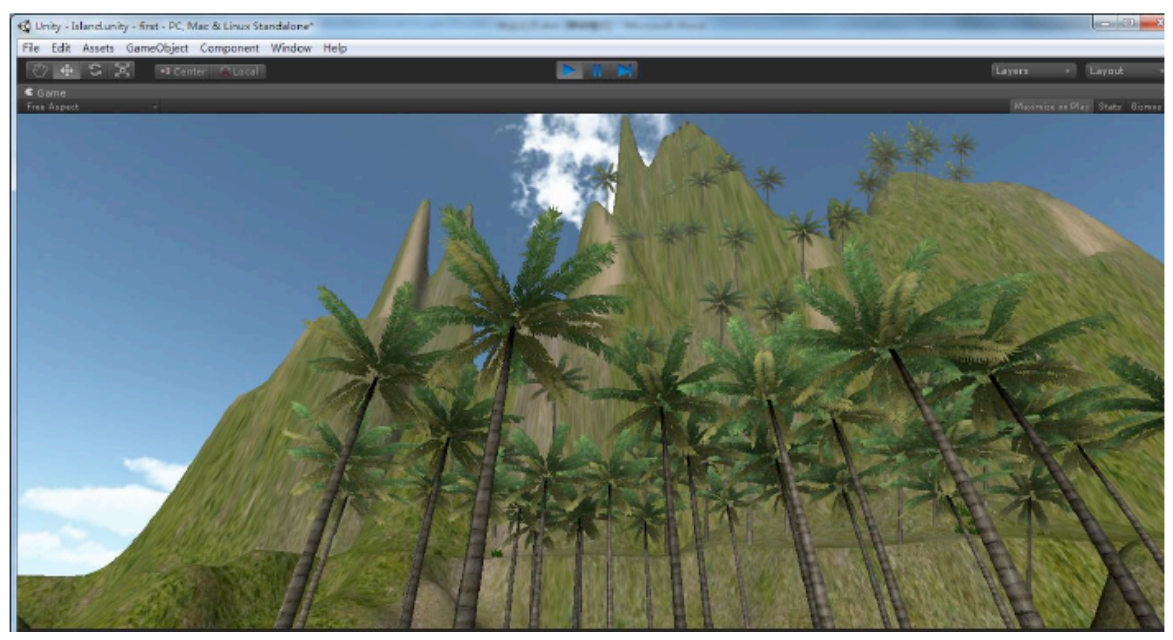

Fig. 6. VR service interface

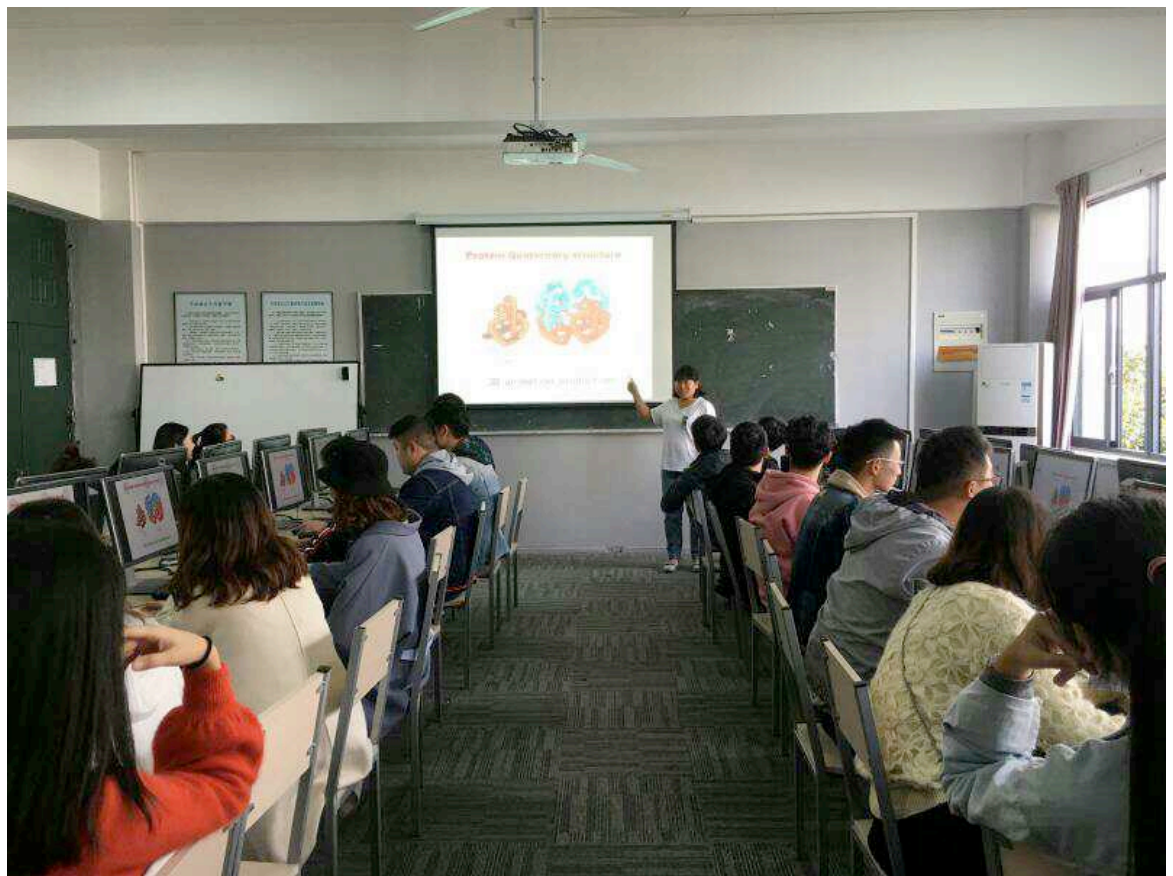

Fig. 7. Teaching procedure demonstration integrating VR technology and teaching 


\subsection{Effect check}

To complete the verification of teaching effect, select 80 students in a class of 2016 animation production specialty in a college as the experiment object. Divide them into two groups based on their previous scores, 40 people in group A and group B. New virtual teaching software is used in group A for 3D animation production course teaching. Traditional teaching method is used in group B. Due to the similar scores and performance in both groups, the influence of early stage factor on teaching effect can be eliminated. The specific experiment effect can be divided into two parts: comparison of year-end evaluation performance of students in two groups; questionnaire survey on students in group A. The statistics use the feedback of teaching condition after using virtual teaching software to obtain the experiment data in table 1 and table 2. Table 1 show the score comparison of students in two groups. Table 2 shows the feedback from students in group A.

It can be seen from table 1 that students in group A are more than group B in average score, excellent and fair number, which shows that new teaching software can improve students' score and it is more suitable for 3D animation production course teaching demand compared with traditional teaching method.

Table 1. Students' interest in finance and accounting knowledge learning $(\mathrm{N}=46)$

\begin{tabular}{|l|c|c|c|c|c|}
\hline & Excellent(n) & Good(n) & Pass(n) & Fail(n) & Average score \\
\hline Group A & 14 & 16 & 6 & 4 & 86.5 \\
\hline Group B & 8 & 10 & 9 & 13 & 72.1 \\
\hline difference & +6 & +6 & -3 & -9 & +14.4 \\
\hline
\end{tabular}

Table 2. feedback of teaching condition

\begin{tabular}{|l|l|l|}
\hline \multicolumn{1}{|c|}{ Evaluation index } & \multicolumn{1}{|c|}{ Item content } & \multicolumn{1}{c|}{ Result } \\
\hline Motive & Experimental design & $87 \%$ students are interested in virtual class \\
\hline \multirow{2}{*}{$\begin{array}{l}\text { Knowledge and } \\
\text { experiment process }\end{array}$} & Knowledge understanding & $\begin{array}{l}85 \% \text { students think new system is good for understand- } \\
\text { ing instruction contents }\end{array}$ \\
\cline { 2 - 3 } & Experimental feasibility & $98 \%$ students can complete virtual experiments \\
\hline $\begin{array}{l}\text { Teacher-student } \\
\text { interaction }\end{array}$ & Interaction feasibility & $\begin{array}{l}85 \% \text { students think new system can promote interaction } \\
\text { with teachers }\end{array}$ \\
\hline
\end{tabular}

It can be seen from table 2 that virtual teaching system is popular among students who unanimously think virtual class can help students better understand and master knowledge, promote the interaction with teachers, and improve students' learning activity.

Auxiliary function application of new teaching system is mainly reflected in following three aspects:

1. The system integrating school teaching resources can convert traditional paper resources into stereo, intuitive and attractive digital VR resources which can attract students' automatic learning, pre-view and prepare before class, and review, practice after class based on these resources. 
2. In classroom teaching, through the system network platform, teachers can know students' learning schedule based on their schoolwork completion condition so as to timely adjust teaching process. Vivid display of theoretical instruction through VR technology can be provided at class. Students can operate and practice with team as unit through virtual lab and timely master skills through simulation training. Teachers can provide guidance for students timely to strengthen the communication during classroom teaching.

3. Students can absorb and digest knowledge they have learned through the teaching system, understand the difficult problems of knowledge points because virtual teaching system can turn some unobservable and invisible phenomenon in real work into visible and vivid perceptual learning materials through $3 \mathrm{D}$ modelling and VR technology. For example, students feel difficult when learning to draw a tiger model due to their incomprehension of its detailed appearance features. VR technology can make students feel like staying with the tiger in the forest so as to observe it carefully and solve the problem of starting from nowhere.

\section{Conclusions}

This paper has proposed to design a set of new teaching system combining SOA design and VR technology aiming at solving problems in current $3 \mathrm{D}$ animation production course teaching for assisting classroom teaching and changing traditional teaching method. Teaching experiment shows that, new teaching system can improve teaching quality, improve students' learning autonomy, and help them to understand questions of important and difficult points in class.

\section{References}

[1] Guo, Y.G. Use of 3D Computer Animation Technology in TV Program Production. Canadian Social Science, 2014, vol. 10(4), pp. 111-114.

[2] Park, S.D., Jung, Y.J. Analysis and Proposal of Abstractive Expression of 3D Animation. Cartoon and Animation Studies, 2014, vol. 37, pp. 1-24. https://doi.org/10.7230/KOSCAS. 2014.37.001

[3] Ji, Y.Y., Liu, Y.J. Development of Intelligent Teaching System Based on 3D Technology in the Course of Digital Animation Production. International Journal of Emerging Technologies in Learning, 2016, vol. 11(9), pp. 81-86. https://doi.org/10.3991/ijet.v11i09.6116

[4] Chen, Z.G., Lu, X.B. Reformation and Development of Information and Interaction Design Based on the Big Data. Packaging Engineering, 2015, vol. 8, pp. 6-9.

[5] Li, L. Digital Television Front-end Design of Virtual Teaching Platform under the Rich Media Environment. China Digital Cable TV, 2013, vol. 2, pp. 152-154.

[6] Tatli, Z., Ayas, A. Virtual Chemistry Laboratory: Effect of Constructivist Learning Environment. Turkish Online Journal of Distance Education, 2012, vol. 13(1), pp. 183-199.

[7] Yang, K.Y., Heh, J.S. The Impact of Internet Virtual Physics Laboratory Instruction on the Achievement in Physics, Science Process Skills and Computer Attitudes of 10th-Grade Students. Journal of Science Education \& Technology, 2007, vol. 16(5), pp. 451-461. https://doi.org/10.1007/s10956-007-9062-6 
[8] Zhu, R., \& Wang, Y. Design and realization of virtual classroom. Journal of Advances in Information Technology, 2012, vol. 3(1), pp. 24-28. https://doi.org/10.4304/jait.3.1.24-28

[9] Huang, H.J., Du, L. Study on SOA-based Architecture of Closed-loop Supply Chain Management Information System. Manufacture Information Engineering of China, 2012, vol. 41(1), pp. 9-12.

[10] Boyd, C.M., Nah, T., Xu, L., et al. Secondary Organic Aerosol (SOA) from Nitrate Radical Oxidation of Monoterpenes: Effects of Temperature, Dilution, and Humidity on Aerosol Formation, Mixing, and Evaporation. Environmental science \& technology, 2017, vol. 51(14), pp. 7831-7841. https://doi.org/10.1021/acs.est.7b01460

\section{$7 \quad$ Authors}

Zhenyan Qin is a Lecturer of Anhui Jianzhu University, Hefei 230022, Anhui, China. Her research interests include 3D Animation. (zhenyanqin66@yeah.net)

Zonghua Tao is a lecturer of Anhui Sanlian University, Hefei 230601, Anhui, China. His research interests include 3D Animation Design. (yingyushiping@126.com)

Article submitted 13 February 018. Final acceptance 25 March 2018. Final version published as submitted by the authors. 